\title{
Kandungan Pewarna, Pengawet, Dan Pemanis Pada Carica In Sirup Kemasan Cup Di Kecamatan Mojotengah, Kabupaten Wonosobo
}

\author{
The Content of Preservatives, Sweeteners, and Dyes in Carica In Cup Packaging Syrup in \\ Mojotengah District, Wonosobo Regency
}

\author{
Nency Kristanti ${ }^{1}$, Dewi Larasati ${ }^{2}$, Ika Fitriana ${ }^{3}$ \\ Teknologi Hasil Pertanian Universitas Semarang
}

\begin{abstract}
ABSTRAK
Produk carica in sirup yang tersusun atas komponen buah carica, air, dan gula. Produk ini merupakan produk dengan kadar air tinggi sehingga cepat rusak selama penyimpanan. Oleh karena itu, untuk memperpanjang umur simpan serta meningkatkan mutu produk, diperlukan bahan tambahan pangan (BTP). Adanya kecenderungan penggunaan bahan tambahan pangan seperti pewarna, pengawet, dan pemanis oleh para produsen carica resiko kesehatan bila mengkonsumsi produk tersebut. Maka dari itu, perlu dilakukan penelitian survey tentang penggunaan bahan tambahan pangan (BTP) seperti pewarna, pengawet, dan pemanis pada produk carica in sirup di Kecamatan Mojotengah, Kabupaten Wonosobo. Tujuan dari penelitian ini adalah untuk mengetahui kandungan bahan tambahan pangan meliputi pewarna (Tartrazin, Kuning FCF), pengawet (Asam Benzoat, Asam Sorbat), dan pemanis (sakarin) yang digunakan pada manisan carica in sirup di Kecamatan Mojotengah, Kabupaten Wonosobo. Penelitian dilaksanakan pada bulan November 2019-Februari 2020 di Laboratorium Kimia pada Balai Besar Pengawas Obat dan Makanan Semarang, Provinsi Jawa Tengah, menggunakan bahan baku carica dalam sirup yang diperoleh dari Kabupaten Wonosobo. Penelitian dilakukan menggunakan survey dengan metode sampling. Untuk menentukan sampel dengan metode sampling maka seluruh populasi sampel yang jumlahnya kurang dari 100 dijadikan subjek penelitian. Hasil penelitian menunjukkan bahwa hasil kuisioner menunjukkan bahwa tingkat pengetahuan perusahaan tentang Bahan Tambahan Pangan 80\% sudah tahu. Dan dari hasil survey menunjukkan bahwa perusahaan yang menggunakan pengawet $40 \%$, pewarna $60 \%$ dan memenuhi persyaratan.
\end{abstract}

Kata Kunci: Bahan Tambahan Pangan (BTP), carica dalam sirup

\section{ABSTRACT}

Carica in syrup products are composed of components of Carica fruit, water, and sugar. This product is a product with high water content so that it breaks easily during storage. Therefore, to extend shelf life and improve product quality, food additives (BTP) are needed. The tendency of using food additives such as dyes, preservatives, and sweeteners by carica producers in syrups, consumers will have health risks when consuming these products. Therefore, survey research needs to be done on the use of food additives (BTP) such as dyes, preservatives, and sweeteners on carica in syrup products in Mojotengah District, Wonosobo Regency. The purpose of this study was to determine the content of food additives including dyes (Tartrazin, Yellow FCF), preservatives (Benzoic Acid, Sorbic Acid), and sweeteners (saccharin) used in carica in syrup sweets in Mojotengah District, Wonosobo Regency. The research was carried out in November 2019 - February 2020 at the Chemical Laboratory at the Center for Drug and Food Inspection in Semarang, Central Java Province, using carica raw materials in syrup obtained from Wonosobo Regency. The study was conducted using a survey with a 
sampling method. To determine the sample by the sampling method, the entire sample population of less than 100 is subject to the study. The results showed that the results of the questionnaire showed that the level of company knowledge about Food Additives $80 \%$ already knew. And from the survey results show that companies that use preservatives $40 \%$, coloring $60 \%$ and meet the requirements.

\section{PENDAHULUAN}

Industri rumah tangga merupakan usaha dalam skala kecil dengan alat dan tenaga kerja yang terbatas. Sebagaimana menurut Badan Pengawasan Obat dan Makanan tahun 2015 mengatakan: "Industri rumah tangga sebagai suatu perusahaan pangan yang memiliki tempat usaha ditempat tinggal dengan peralatan pengolahan pangan manual hingga semi otomatis". Industri rumah tangga memperkerjakan seseorang untuk memproduksi usahanya, sehingga industri rumah tangga berperan dalam mengatasi pengangguran.

Usaha rumah tangga yang bermunculan memproduksi beraneka jenis minuman kemasan khususnya produk carica in sirup kemasan cup. Sesama pengusaha atau produsen terjadinya persaingan dalam memasarkan produknya. Kecenderungan konsumen memilih produk dengan warna yang cerah, rasa yang manis serta tahan lama, menuntut produsen lebih kreatif dalam memproduksi hasil produknya.

Cara yang dilakukan produsen agar hasil produknya tetap laku dengan menambahkan Bahan Tambahan Pangan (BTP) ke dalam hasil produknya. BTP adalah menurut Peraturan Menteri Kesehatan RI No.722/ Menkes/ Per/ IX/88 dijelaskan bahwa bahan yang biasanya tidak digunakan sebagai makanan dan biasanya bukan merupakan bahan khas pangan, mempunyai atau tidak mempunyai nilai gizi, yang dengan sengaja ditambahkan ke dalam pangan untuk maksud teknologi pada pembuatan, pengolahan, penyiapan, perlakuan, pengepakan, pengemasan, penyimpanan atau pengangkutan pangan untuk menghasilkan suatu komponen atau mempengaruhi sifat khas pangan tersebut.

Berdasarkan observasi pendahuluan, ditemukan fakta bahwa, banyaknya ditemukan produsen industri rumah tangga menggunakan BTP sintetis pada pengolahan produknya seperti pewarna, pemanis, dan pengawet. Tujuan produsen menggunakan BTP sintetis agar tampilan produk lebih bagus, berwarna cerah, gurih dan manis. Penggunaan BTP sintetis juga dapat menghemat ongkos produksi dan menghemat waktu, sedangkan penggunaan BTP sintetis yang tidak berdasarkan takaran atau jumlah yang seharusnya dapat membahayakan kesehatan.

Adanya kecenderungan penggunaan bahan tambahan pangan seperti pewarna, pengawet, dan pemanis oleh para produsen carica dalam sirup, maka konsumen akan memiliki resiko kesehatan bila mengkonsumsi produk tersebut. Hal inilah yang melatarbelakangi penulis untuk melakukan penelitian tentang tentang penggunaan bahan tambahan pangan (BTP) seperti pewarna, pengawet, dan pemanis pada produk carica in sirup kemasan cup di Kecamatan Mojotengah, Kabupaten Wonosobo. 


\section{METODOLOGI PENELITIAN}

\section{Bahan dan Alat}

Bahan utama yang digunakan adalah carica in sirup kemasan cup yang dibeli dari 10 industri carica yang berada di Kecamatan Mojotengah, Kabupaten Wonosobo. Bahan analisa yang digunakan untuk penelitian pengawet dan pewarna adalah membuat larutan dapar fosfat $\mathrm{pH} 6,8$ adalah $\mathrm{KH}_{2} \mathrm{PO}_{4}$ dan $\mathrm{K}_{2} \mathrm{HPO}_{4}$, air derajat $\mathrm{KCKT}$, dan $\mathrm{CH}_{3} \mathrm{OH}$.

Alat yang digunakan pada penelitian ini meliputi Kromatografi Cair Kinerja Tinggi (KCKT) yang dilengkapi dengan kolom C18 (150 $\mathrm{mm}$ x 4,6 mm) ukuran partikel 2,7 $\mu \mathrm{m}$, detektor $\mathrm{UV}$; labu tentukur 20, 50, dan $100 \mathrm{ml}$; pipet mikro volume 20-200 $\mu$ l dan 100-1000 $\mu$; pipet volumetric 2,4,6,8 dan $10 \mathrm{ml}$.

\section{Prosedur Penelitian}

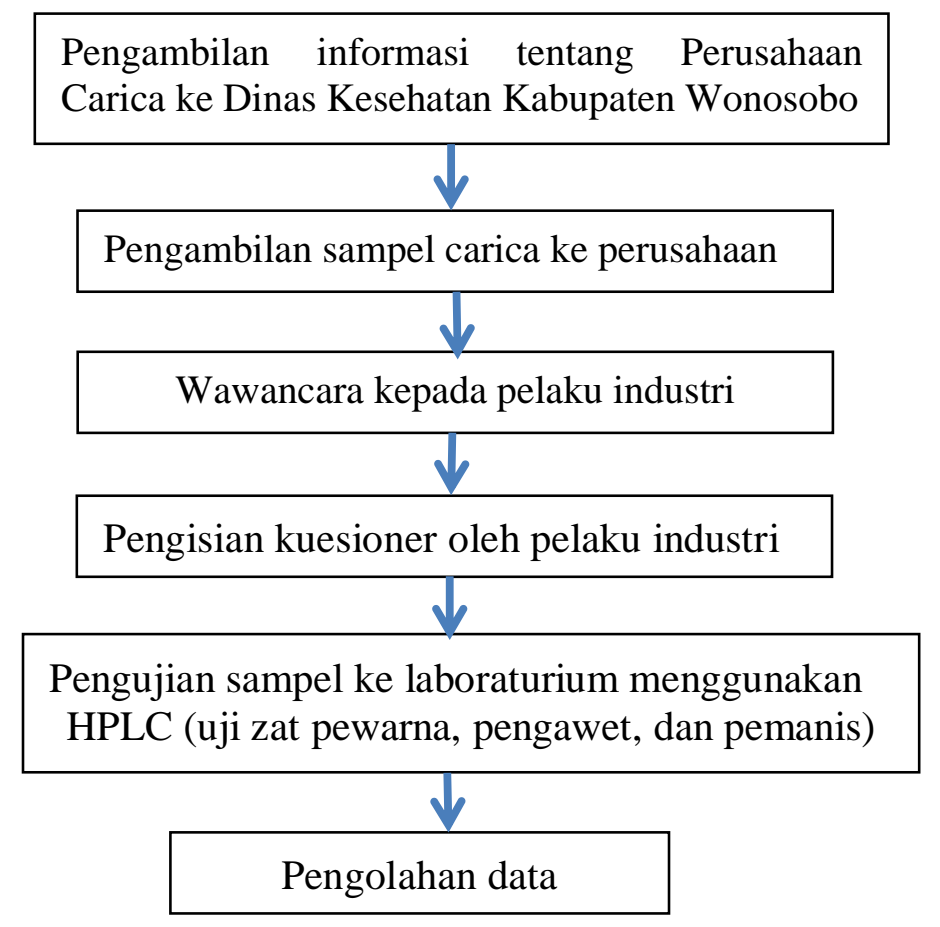

Gambar 1. Diagram alir tahapan penelitian (sumber : peneliti, 2020)

\section{HASIL DAN PEMBAHASAN}

\section{Hasil kuesioner}

Hasil kuesioner menunjukkan bahwa pemahaman responden terhadap bahan tambahan pangan (BTP) adalah $80 \%$ tahu, dan $20 \%$ responden kurang memahami dan tidak mengetahui BTP. Untuk melihat apakah kuesioner yang telah dibuat dapat dipahami dengan baik oleh responden, menggunakan 8 butir pertanyaan dengan jawaban singkat dari responden. 
Analisis ini dilakukan secara deskriptif, yaitu dengan mentabulasikan jawaban responden kemudian diinterpretasikan. Butir pertanyaan 1, sebanyak 80\% atau 8 dari 10 responden tahu mengenai istilah BTP, responden mengetahui istilah BTP yang merupakan bahan tambahan pangan yang sengaja ditambahkan dan tidak memiliki nilai gizi. Kemudian untuk butir pertanyaan 2, sebanyak $80 \%$ atau 8 dari 10 responden mengetahui yang dimaksud dengan BTP yaitu untuk memperbaiki penampakan, warna, bentuk, cita rasa, tekstur, flavour dan memperpanjang daya simpan. Untuk butir pertanyaan 3 hanya $10 \%$ atau 1 dari 10 responden yang memiliki pengetahuan mengenai merek lain dari jenis BTP yang beredar dipasaran. misalnya terdapat natrium benzoat dengan merek koepu-koepu, merek apel, pewarna serbuk alco dan pewarna cair rajawali. Untuk butir pertanyaan 4 hanya $60 \%$ atau 6 dari 10 responden yang mengetahui bahwa bahwa BTP yang digunakan termasuk kelompok tertentu yaitu BTP yang diizinkan dan yang tidak dizinkan. Untuk butir pertanyaan 5, sebanyak 80\% atau 8 dari 10 responden mengetahui fungsi dari BTP yang digunakan, artinya responden memiliki pengetahuan tentang penggolongan BTP, penggunaan. Butir pertanyaan $6,80 \%$ atau 8 dari 10 responden yang memiliki pengetahuan BTP yang tepat dapat menjamin mutu dan keamanan produknya, takaran pemakaian yang tepat tidak menimbulkan gangguan kesehatan. Butir pertanyaan 7, 80\% atau 8 dari 10 responden mengetahui penggunaan BTP yang salah dapat mempengaruhi mutu dan keamanan produknya, misalnya pemakaian berlebih dapat menimbulkan rasa pahit pada produk. Butir pertanyaan $8,80 \%$ atau 8 dari 10 responden mengetahui BTP yang digunakan serta diijinkan oleh pemerintah, yaitu BTP yang telah memiliki izin edar dari BPOM.

\section{Analisis Hasil Uji Validitas dan Reliabilitas Uji Validitas}

Hasil Uji Validitas Instrumen penelitian yang digunakan oleh penulis dalam penelitian ini adalah kuesioner atau angket. Penulis mengambil langkah untuk melakukan uji validitas untuk mengetahui seberapa besar kevalidan dari alat ukur yang digunakan dengan analisis validitas metode bivariate correlation product moment dengan bantuan program statistik SPSS 16 for Windows. Berdasarkan hasil perhitungan uji validitas dengan 8 item pertanyaan adalah sebagai berikut:

Tabel 1. Hasil uji validitas

\begin{tabular}{|l|l|l|l|}
\hline Butir Pertanyaan & $\begin{array}{l}\text { Nilai Corrected Item Total } \\
\text { Correlation / rhitung }\end{array}$ & R Tabel & Kriteria \\
\hline 1 & 0,709 & 0,707 & Valid \\
\hline 2 & 0,785 & 0,707 & Valid \\
\hline 3 & 0,794 & 0,707 & Valid \\
\hline 4 & 0,800 & 0,707 & Valid \\
\hline 5 & 0,785 & 0,707 & Valid \\
\hline 6 & 0,925 & 0,707 & Valid \\
\hline 7 & 0,926 & 0,707 & Valid \\
\hline 8 & 0,742 & 0,707 & Valid \\
\hline
\end{tabular}

Sumber : Data primer yang diolah 
Berdasarkan Tabel 1., maka dapat dilihat bahwa seluruh pertanyaan memiliki nilai Rhitung > Rtabel sebesar 0,707. Sehingga setiap pertanyaan yang digunakan penulis dalam kuesioner sudah memenuhi validitas.

\section{Uji Reabilitas}

Uji reliabilitas dilakukan terhadap item pertanyaan yang dinyatakan valid. Suatu variabel dikatakan reliabel atau handal jika jawaban terhadap pertanyaan selalu konsisten. Koefisien reliabilitas instrumen dimaksudkan untuk melihat konsistensi jawaban butir-butir pernyataan yang diberikan oleh responden Adapun alat analisisnya menggunakan metode belah dua (split half) dengan mengkorelasikan total skor ganjil lawan genap, selanjutnya dihitung reliabilitasnya menggunakan rumus“Alpha Cronbach'. Penghitungan dilakukan dengan dibantu komputer program SPSS. Adapun reliabilitas untuk pertanyaan hasilnya disajikan pada tabel berikut ini.

Tabel 2. Hasil uji reliabilitas

\begin{tabular}{|l|l|l|}
\hline R alpha & R kritis (lihat tabel) & N \\
\hline 0,836 & 0,707 & 8 \\
\hline
\end{tabular}

Berdasarkan Tabel 2. Uji reliabilitas dilakukan terhadap seluruh item pertanyaan yang dinyatakan valid. Suatu variabel dikatakan reliabel atau handal jika jawaban terhadap pertanyaan selalu konsisten. Jadi hasil koefisien reliabilitas sebesar 0,836, dan ternyata memiliki nilai "Alpha Cronbach" lebih besar dari 0,707, yang berarti kuesioner dinyatakan reliable atau memenuhi persyaratan.

\section{Karakteristik Industri Carica in Sirup di Kecamatan Mojotengah, Kabupaten Wonosobo}

Pengambilan sampel dilakukan pada 10 industri Carica in sirup kemasan cup, langsung dilakukan pengujian menggunakan Kromatografi Cair Kinerja Tinggi yang diuji pewarna, pengawet dan pemanis. Banyaknya produk carica dengan merk yang berbeda di pasaran membuat konsumen bersaing untuk meningkatkan daya tahan carica in sirup kemasan cup dengan menambahkan bahan tambahan pangan. Bahan tambahan pangan yang digunakan carica in sirup kemasan cup adalah pewarna, pengawet dan pemanis. Berikut ini adalah sampel 10 industri yang akan digunakan : 
Tabel 3. Sampel industri yang digunakan

\begin{tabular}{cccccccc}
\hline $\begin{array}{c}\text { No. } \\
\text { Urut } \\
\text { Sampel }\end{array}$ & $\begin{array}{c}\text { Nama } \\
\text { Perusaha } \\
\text { an }\end{array}$ & $\begin{array}{c}\text { Nama } \\
\text { Pemilik }\end{array}$ & $\begin{array}{c}\text { Alamat } \\
\text { Perusahaan }\end{array}$ & $\begin{array}{c}\text { Nama } \\
\text { Responden }\end{array}$ & Pewarna & Pengawet & Pemanis \\
\hline 1 & $\mathrm{~A}$ & $\mathrm{Aa}$ & Mojotengah & $\mathrm{Aa}$ & - & - & - \\
2 & $\mathrm{~B}$ & $\mathrm{Ba}$ & Mojotengah & $\mathrm{Bb}$ & - & - & - \\
3 & $\mathrm{C}$ & $\mathrm{Ca}$ & Mojotengah & $\mathrm{Cb}$ & Tartrazin & - & - \\
4 & $\mathrm{D}$ & $\mathrm{Da}$ & Mojotengah & $\mathrm{Db}$ & Tartrazin & Asam benzoat & - \\
5 & $\mathrm{E}$ & $\mathrm{D}$ & Mojotengah & $\mathrm{D}$ & Tartrazin & Asam benzoat & - \\
6 & $\mathrm{~F}$ & $\mathrm{Fa}$ & Mojotengah & $\mathrm{Fb}$ & Tartrazin & - & - \\
7 & $\mathrm{G}$ & $\mathrm{Ga}$ & Mojotengah & $\mathrm{Gb}$ & Tartrazin & Asam benzoat & - \\
8 & $\mathrm{H}$ & $\mathrm{Ha}$ & Mojotengah & $\mathrm{Hb}$ & Tartrazin & Asam benzoat & - \\
9 & $\mathrm{I}$ & $\mathrm{Ia}$ & Mojotengah & $\mathrm{Ia}$ & - & - & - \\
10 & $\mathrm{~J}$ & $\mathrm{Ja}$ & Mojotengah & $\mathrm{Jb}$ & - & - & - \\
\hline
\end{tabular}

Menurut (Waheni, 2009) pemakaian pewarna, pengawet dan pemanis yang berlebih dapat menimbulkan penyakit kulit dermatitis, asma, artikaria (biduran). Dengan adanya berbagai permasalahan seperti tersebut di atas, maka penggunaan pewarna, pengawet dan pemanis dalam makanan dan minuman perlu dibatasi.

Penggunaan Zat Pewarna pada Industri Carica in Sirup di Kecamatan Mojotengah Kabupaten Wonosobo

Hasil pengujian penggunaan zat pewarna dari 10 Industri Carica yang berada di Kecamatan Mojotengah Kabupaten Wonosobo dapat dilihat pada Tabel 4 dan 5.

Tabel 4. Hasil uji zat pewarna Tartrazin yang digunakan pelaku industri

\begin{tabular}{|l|l|c|c|c|}
\hline No & $\begin{array}{l}\text { Sampel } \\
\text { Industri }\end{array}$ & $\begin{array}{l}\text { Jenis Tartrazin } \\
\text { yang terdeteksi }\end{array}$ & $\begin{array}{l}\text { Kadar Tartazin } \\
\text { terdeteksi }(\mathrm{mg} / \mathrm{kg})\end{array}$ & $\begin{array}{l}\text { Batas penggunaan } \\
\text { maksimum } \\
(\mathrm{mg} / \mathrm{kg})\end{array}$ \\
\hline 1 & Industri A & - & - & \\
\hline 2 & Industri B & - & - & \\
\hline 3 & Industri C & + & $3,37 \pm 0,43$ & \\
\hline 4 & Industri D & + & $18,46 \pm 0,33$ & \\
\hline 5 & Industri E & + & $8,32 \pm 0,13$ & 70 \\
\hline 6 & Industri F & + & $1,67 \pm 0,04$ & \\
\hline 7 & Industri G & + & $1,80 \pm 0,07$ & \\
\hline 8 & Industri H & + & $3,36 \pm 0,13$ & \\
\hline 9 & Industri I & - & & \\
\hline 10 & Industri J & - & & \\
\hline
\end{tabular}

$-=$ Tidak terdeteksi $\quad+=$ Terdeteksi 
Tabel 5. Hasil uji zat pewarna kuning FCF yang digunakan pelaku industri

\begin{tabular}{|l|l|c|c|}
\hline No & $\begin{array}{l}\text { Sampel } \\
\text { Industri }\end{array}$ & $\begin{array}{l}\text { Jenis kuning FCF } \\
\text { yang } \\
(\mathrm{mg} / \mathrm{kg})\end{array}$ & $\begin{array}{c}\text { Batas penggunaan } \\
\text { terdeteksi }\end{array}$ \\
\hline 1 & Industri A & - & \\
\hline 2 & Industri B & - & \\
\hline 3 & Industri C & - & 50 \\
\hline 4 & Industri D & - & \\
\hline 5 & Industri E & - & \\
\hline 6 & Industri F & - & \\
\hline 7 & Industri G & - & \\
\hline 8 & Industri H & - & \\
\hline 9 & Industri I & - & \\
\hline 10 & Industri J & - & \\
\hline
\end{tabular}

Berdasarkan Tabel 4. Diatas dapat dilihat bahwa pada 6 sampel carica in sirup kemasan cup (6\% sampel carica in sirup kemasan cup) menggunakan pewarna tartrazin. Kadar tatrazine yang didapatkan dari penelitian ini untuk industri C sebesar 3,37 $\mathrm{mg} / \mathrm{kg}$; industri D sebesar $18,46 \mathrm{mg} / \mathrm{kg}$; industri E sebesar $8,32 \mathrm{mg} / \mathrm{kg}$; industri F sebesar $1,67 \mathrm{mg} / \mathrm{kg}$; industri $\mathrm{G}$ sebesar $1,80 \mathrm{mg} / \mathrm{kg}$; industri $\mathrm{H}$ sebesar $3,36 \mathrm{mg} / \mathrm{kg}$. Persyaratan batas kadar maksimum untuk jenis pewarna tartrazine tidak diperbolehkan melebihi $70 \mathrm{mg} / \mathrm{kg}$, sedangkan untuk kuning FCF sebesar $50 \mathrm{mg} / \mathrm{kg}$ untuk produk siap dikonsumsi untuk minuman dan makanan cair sesuai dengan Peraturan Badan Pengawas Obat dan Makanan No.11 Tahun 2019. Berdasarkan tabel 4. menunjukkan bahwa 6 industri carica menggunakan kadar zat pewarna tartrazine masih dibawah batas maksimum yang diizinkan dalam kata lain kadar zat pewarna yang dikandung dalam masing-masing sampel aman dikonsumsi oleh masyarakat. Tartrazine merupakan pewarna kuning lemon sintetis yang biasa digunakan sebagai pewarna makanan. Tartrazine termasuk jenis pewarna yang masih diperbolehkan untuk digunakan dalam batas aman penggunaan (Indrie dkk, 2014).

Kemudian hasil penelitian (tabel 5) menunjukkan untuk penggunaan zat pewarna kuning FCF tidak terdeteksi pada semua sampel. Adapun Kuning FCF tidak dilarang penggunaannya, namun dianjurkan untuk dihindari penggunaannya karena dapat menyebabkan reaksi alergi pada manusia dan hiperaktif pada anak-anak. (Nurjanah et al., 1992).

\section{Penggunaan Zat Pengawet pada Industri Carica in Sirup di Kecamatan Mojotengah Kab Wonosobo}

Hasil pengujian penggunaan pengawet dari 10 industri carica in sirup kemasan cup di Kecamatan Mojotengah Kabupaten Wonosobo dapat dilihat pada tabel 6. 
Tabel 6. Hasil uji zat pengawet asam benzoat yang digunakan pelaku industri

\begin{tabular}{|l|l|l|l|l|}
\hline No & $\begin{array}{l}\text { Sampel } \\
\text { Industri }\end{array}$ & $\begin{array}{l}\text { Jenis Asam } \\
\text { Benzoat yang } \\
\text { terdeteksi } \\
(\mathrm{mg} / \mathrm{kg})\end{array}$ & $\begin{array}{l}\text { Jenis Tartrazin } \\
\text { yang terdeteksi }\end{array}$ & $\begin{array}{l}\text { Batas penggunaan } \\
\text { maksimum } \\
(\mathrm{mg} / \mathrm{kg})\end{array}$ \\
\hline 1 & Industri A & - & - & \\
\hline 2 & Industri B & - & - & \\
\hline 3 & Industri C & - & $191,56 \pm 2,06$ & \\
\hline 4 & Industri D & + & $186,47 \pm 1,38$ & 200 \\
\hline 5 & Industri E & + & - & \\
\hline 6 & Industri F & - & $185,98 \pm 1,11$ & \\
\hline 7 & Industri G & + & $184,12 \pm 1,56$ & \\
\hline 8 & Industri H & + & - & \\
\hline 9 & Industri I & - & - & \\
\hline 10 & Industri J & - & & \\
\hline
\end{tabular}

- = Tidak terdeteksi $\quad+=$ Terdeteksi

Tabel 7. Hasil uji zat pengawet asam sorbatt yang digunakan pelaku industri

\begin{tabular}{|c|c|c|c|c|}
\hline No & $\begin{array}{l}\text { Sampel } \\
\text { Industri }\end{array}$ & $\begin{array}{ll}\text { Jenis } & \text { Asam Sorbat } \\
\text { yang } & \text { terdeteksi } \\
(\mathrm{mg} / \mathrm{kg}) & \end{array}$ & $\begin{array}{lr}\text { Kadar } & \text { Asam } \\
\text { Sorbat } & \text { yg } \\
\text { terdeteksi } & \end{array}$ & $\begin{array}{l}\text { Batas penggunaan } \\
\text { maksimum }(\mathrm{mg} / \mathrm{kg})\end{array}$ \\
\hline 1 & Industri A & - & - & \\
\hline 2 & Industri B & - & - & \\
\hline 3 & Industri C & - & - & \\
\hline 4 & Industri D & - & - & \\
\hline 5 & Industri E & - & - & 1000 \\
\hline 6 & Industri F & - & - & \\
\hline 7 & Industri $\mathrm{G}$ & - & - & \\
\hline 8 & Industri $\mathrm{H}$ & - & - & \\
\hline 9 & Industri I & - & - & \\
\hline 10 & Industri J & - & - & \\
\hline
\end{tabular}

- = Tidak terdeteksi $\quad+=$ Terdeteksi

Berdasarkan Tabel 6. dapat dilihat bahwa pada 10 sampel carica in sirup kemasan cup (4\% sampel carica in sirup kemasan cup) menggunakan pengawet asam benzoat. Kadar yang didapatkan dari penelitian ini untuk industri D sebesar 191,56 mg/kg; industri E sebesar 186,47 $\mathrm{mg} / \mathrm{kg}$; industri $\mathrm{G}$ sebesar 185,98 mg/kg ; industri $\mathrm{H}$ sebesar $184,12 \mathrm{mg} / \mathrm{kg}$. Menurut Peraturan Badan Pengawas Obat dan Makanan No.11 Tahun 2019, kadar asam benzoat tidak boleh lebih dari $200 \mathrm{mg} / \mathrm{kg}$. 
Kadar asam benzoat pada carica in sirup kemasan cup dari setiap sampel memenuhi persyaratan kadar pengawet asam benzoat yaitu tidak lebih dari $200 \mathrm{mg} / \mathrm{kg}$ sehingga dapat dikonsumsi oleh masyarakat. Alasan dilakukan penelitian ini untuk mengetahui kadar asam benzoat yang terdapat pada carica in sirup kemasan cup telah memenuhi persyaratan yang telah ditentukan dan bahaya pengawet asam benzoat bila dikonsumsi berlebihan. Terutama pada penderita asma dan urtikaria, jika dikonsumsi dalam jumlah besar akan mengiritasi lambung (Chipley, 2005). Asam benzoat digunakan sebagai senyawa antimikrobia pada makanan karena tujuan penggunaan zat pengawet untuk mencegah pertumbuhan ragi dan bakteri (Desrosier, 1988).

Berdasarkan Peraturan Menteri Kesehatan RI No. 722/ Menkes/ Per/ IX/ 1988, asam sorbat digunakan pada sediaan keju olahan dengan batas maksimum $3000 \mathrm{mg} / \mathrm{kg}$. Sedangkan pada produk keju, margarin, acar ketimun dalam botol, jem dan jeli serta pekatan sari nenas, batas maksimum penggunaanya sebesar $1000 \mathrm{mg} / \mathrm{kg}$. Nilai ADI dari pengawet kalium sorbat adalah 0-25 mg/kg bobot badan (JECFA 2005). Berdasarkan hasil penelitian menunjukkan bahwa untuk penggunaan zat pengawet asam sorbat tidak terdeteksi pada semua sampel.

\section{Penggunaan Zat Pemanis pada Industri Carica in Sirup di Kecamatan Mojotengah Kabupaten Wonosobo}

Hasil pengujian penggunaan pemanis dari 10 industri carica in sirup yang berada di Kecamatan Mojotengah Kabupaten Wonosobo dapat dilihat pada Tabel 8. Menurut Eriawan R. dalam Cahyadi, (2009:76) mengatakan bahwa: "Pemanis merupakan senyawa kimia yang sering ditambahkan dan digunakan untuk keperluan produk olahan pangan, industri, serta minuman dan makanan kesehatan".

Dapat dilihat pada tabel 8 . bahwa pada 10 sampel carica in sirup kemasan cup tidak menggunakan pemanis buatan yaitu sakarin. Penggunaan pemanis yang digunakan oleh pelaku industri carica in sirup kemasan cup menggunakan pemanis alami gula pasir. Dampak dari penggunaan bahan pemanis sintetis, yang tidak berdasarkan jumlah dan takaran yang seharusnya, dapat menyebabkan kerusakan pada tubuh seperti menurut pendapat Nuraini (2007:38) menyatakan bahwa : "Kerusakan gigi adalah salah satu efek yang ditimbulkan oleh rasa manis. Gula pasir merupakan serbuk kristal yang berwarna putih dan berasa manis. Gula pasir terbuat dari sari air batang pohon tebu. Pemanis tersebut aman untuk dikonsumsi karena terbuat dari bahan alami berupa sari air tebu (Usmiati, 2004).

\section{PENUTUP}

\section{Kesimpulan}

Berdasarkan hasil penelitian dan pembahasan maka dapat ditarik suatu kesimpulan sebagai berikut :

1. Terdapat 6 dari 10 sampel carica in sirup kemasan cup yang mengandung zat pewarna tartrazine yang masih dibawah batas maksimum (aman untuk dikonsumsi) dan tidak ditemukan kandungan kuning FCF.

2. Terdapat 4 dari 10 sampel carica in sirup kemasan cup yang mengandung zat pengawet asam benzoat yang masih dibawah batas maksimum (aman dikonsumsi) serta tidak ditemukan asam sorbat dalam sampel.

3. Tidak ditemukan penggunaan pemanis buatan yaitu sakarin pada 10 sampel carica in sirup kemasan cup. 


\section{Saran}

Berdasarkan hasil dari penelitian ini maka didapatkan beberapa saran, yaitu :

1. Dinas Perdagangan dan Perindustrian Kabupaten Wonosobo secara rutin mengadakan pembinaan kepada industri pangan skala menengah dalam rangka pengembangan ilmu pengetahuan.

2. Balai Besar POM di Semarang dan Dinas Kesehatan Kabupaten Wonosobo mengadakan pengawasan terhadap penggunaan Bahan Tambahan Pangan dan sosialisasi yang lebih intensif tentang peraturan penggunaan BTP.

3. Kepada peneliti selanjutnya agar meneliti hygiene dan sanitasi dalam pengolahan makanan industri kecil di Kecamatan Mojotengah Kabupaten Wonosobo.

4. Untuk mendapatkan hasil yang lebih representatif, maka perlu dilakukan penambahan jumlah sampel atau jumlah responden.

\section{DAFTAR PUSTAKA}

(BPOM) Badan Pengawas Obat Dan Makanan. 2019. Bahan Tambahan Pangan. Kepala Badan Pengawas Obat dan Makanan Republik Indonesia.

Cahyadi, W. 2009. Analisis dan Aspek Kesehatan Bahan Tambahan Pangan . Edisi kedua. Jakarta: Bumi Aksara.

Chipley, J. R., 2005. Sodium Benzoate and Benzoic Acid, CRC Press Taylor \& Francis Group, Boca Raton.

Departemen Kesehatan Republik Indonesia. 1988. Peraturan Menteri Kesehatan Republik Indonesia tentang Bahan Tambahan Makanan, Kumpulan Peraturan Perundangundangan di Bidang Makanan (Edisi II). Departemen Kesehatan Republik Indonesia.

Desrosier, N. W. 1988. Teknologi Pengawetan Pangan. Terjemahan: Mulyohardjo, M. UI. Press. Jakarta.

Indrie Ambarsari, Qanytah \& Sarjan. Penerapan Standar Penggunaan Pemanis Buatan Pada Produk Pangan. Warta penelitian Pengkajian Teknologi Pertanian. 2014

[JECFA] Joint FAO/WHO Expert Committee on Food Additives. 2005. Summary of Evaluations Performed by the Joint FAO/WHO Expert Committee on Food Additives. Sorbic acid. http://www.inchem.org/documents/ jecfa/jeceval/jec_2181.htm. [12 Februari 2020]

Nurjanah, I, Sukmaningsih, Setiawan S \& Rustamaji E. 1992. Sebaiknya Anda Tahu Bahan Tambahan Makanan. Jakarta: Yayasan Lembaga Konsumen Indonesia

Usmiati S. dan Yuliani. Pemanis Alami dan Buatan untuk Kesehatan. 2004. Warta Penelitian dan Pengembangan Tanaman Industri 10 (1): 13 - 17.

Waheni, S. 2009. Penentuan kadar Natrium benzoat dalam kecap secara spektrofotometer ultra violet. Universitas Sunan Kalijaga. Yogyakarta. 